anales de psicología, 2017, vol. 33, nº 2 (may), 218-224 http://dx.doi.org/10.6018/analesps.33.2.261911
C) Copyright 2017: Servicio de Publicaciones de la Universidad de Murcia. Murcia (Spain) ISSN print edition: 0212-9728. ISSN web edition (http://revistas.um.es/analesps): 1695-2294

\title{
The Relationships between Big Five Personality Traits and Subjective Vitality
}

\author{
M. Engin Deniz ${ }^{1}$, and Seydi Ahmet Satici2* \\ 1 Yildiz Technical University (Turkey). \\ 2 Artvin Corub University (Turkey).
}

\begin{abstract}
Título: Las relaciones entre los rasgos de personalidad Big Five y la vitalidad subjetiva.

Resumen: El presente estudio examina la relación entre los rasgos de personalidad Big Five y la vitalidad subjetiva. Los participantes fueron 307 estudiantes universitarios [180 (59\%) mujeres, $127(41 \%), M_{\text {edad }}=21.24$ años, $S D=1.21]$, que completaron el grupo de cuestionarios Adjective Bases Personality Scale y el Subjective Vitality Scale. Se empleó un análisis de regresión jerárquica con los rasgos de personalidad big five para explicar la varianza en la vitalidad subjetiva. Los resultados muestran que la extraversión, la agradabilidad y la apertura fueron predictores significativamente positivos y el neuroticismo fue un predictor negativo de la vitalidad subjetiva, explicando el $31 \%$ del total de la rarianza. El nivel de conciencia no fue predictor significativo de la vitalidad subjetiva. Se discute la significación y las limitaciones de los resultados.

Palabras clave: Personalidad Big Five; vitalidad subjetiva; regresión jerárquica; Turquía.
\end{abstract}

\section{Introduction}

All the individuals have personal characteristics and these characteristics which can be labeled as personality influence how they respond to their environment. Personality makes people uniquely themselves (Friedman \& Schustack, 2006) and can be described as "the set of psychological traits and mechanisms within the individual that are organized and relatively enduring and that influence his or her interactions with, and adaptations to, the intra-psychic, physical, and social environments" (Larsen \& Buss, 2005, p.4). Consistently, Allport (1961) discussed personality as an internal construct that has a significant effect on human activities and behaviors and as an important determinant of thoughts. He also accepted this concept as which an individual really is.

Personality has been defined by Ryckman (2008) as a "dynamic and organized set of characteristics possessed by a person that uniquely influences his or her cognitions, motivations, and behaviors in various situations" (p.4). Personality is related to individual differences and it shapes how a person will act, think and feel. As being relatively stable and lasting organization of an individual's character, temperament, body and intellect personality is the main determinant of one's adjustment to environment (Eysenck, 2013). According to the Atkinson and colleagues (1996) personality recognize the way of interaction with physical and social surroundings. It is also can be labeled as specific patterns of thoughts, feelings and behaviors.

Although personality is one of the most comprehensive concept, researchers and psychologist have built a consensus

* Correspondence address [Dirección para correspondencia]: Seydi Ahmet SATICI, Ph.D., Artvin Coruh University, Faculty of Education, Department of Psychological Counseling and Guidance, 08000, Artvin (Turkey). E-mail: sasatici@gmail.com
Abstract: The current study examined the relationship between big five personality traits and subjective vitality. Participant were 307 university students [180 ${ }_{(59 \%)}$ female, $127(41 \%)$ male, $M_{\text {age }}=21.24$ years, $\left.\mathrm{SD}=1.21\right]$ who completed questionnaires package the Adjective Based Personality Scale and the Subjective Vitality Scale. A hierarchical regression analyses was used with big five personality traits to explain variance in subjective vitality. The results showed that extraversion, agreeableness, and openness were significant positive predictors and neuroticism was significant negative predictor of subjective vitality which accounted for $31 \%$ of the total variance. Consciousness did not significant predictor of subjective vitality. The significance and limitations of the results are discussed.

Key words: Big Five personality; Subjective vitality; Hierarchical regression; Turkey.

on basic dimensions of personality and developed a wellaccepted personality structure. Personality can be characterized by a hierarchical system which assumes that there are five major and universal factors of personality, also known as "the Big Five". These factors which summarized in the acronym OCEAN, are Openness to experience, Conscientiousness, Extraversion, Agreeableness and Neuroticism (Costa \& McCrae, 1985, 1992; Digman, 1990; McCrae \& John, 1992). John and Srivastava (1999) claimed that the Big Five taxonomy did not replace all previous systems about personality factor. Contrarily this taxonomy may reflect the different systems of personality description in a common framework thus it plays an integrative role.

Openness to experience makes a distinction between being open to new experiences and being conventional. Individuals who are open to new experiences are willing to be open-minded to new ideas and approaches (Costa \& McCrea, 1985). They are curious, creative, insightful, original, imaginative, and not uncreative. Openness to experience is associated with intellectual curiosity, experiencing new ideas, aesthetic sensitivity, and wide interests and having unusual thought processes (McCrea \& Costa, 1997). Conscientiousness dimension makes a distinction between being conscientious and being careless. Conscientious individuals have high level of organization, persistence, and motivation in goal-directed behavior and may delay gratification. They are punctual, hardworking, reliable, responsible, efficient and not lackadaisical (McCrea \& Costa, 1987). Conscientiousness is associated with self-discipline, productivity, ethical behavior, high aspiration level and achievement striving (Allen, Greenlees \& Jones, 2011; Burger, 2006; Costa \& McCrea, 1985; McCrae \& John, 1992).

Extraversion dimension of personality makes a distinction between being extraverted and being introverted. Individuals who are high in extraversion have more interperson- 
al interactions and tend to experience more positive emotions. They are sociable, outgoing, energetic, talkative, active and not sober. Extraversion is associated with being selfassured, assertive behaviors and excitement seeking. Agreeableness makes a distinction between being good-natured and being cynical (McCrea \& Costa, 1997). Agreeable individuals have prosocial orientation towards others and are not antagonist in thoughts, feelings and actions. They are compassionate, forgiving, kind, trusting and not selfish. Agreeableness is associated with being cooperative and behaving in a giving way. Lastly, neuroticism dimension makes a distinction between being emotionally stable and being emotionally unstable. Individuals who are high in neuroticism are likely to have more psychological distress and experience more negative emotionality. They are anxious, hostile, tense, touchy and not calm. Neuroticism is associated with unrealistic ideas, self-defeating, maladaptive coping responses, and vulnerability to psychological problems (Allen, et al., 2011; Burger, 2006; Costa \& McCrea, 1985; McCrae \& John, 1992).

Previous literature on personality is closely related with positive individual traits and human strengths such as wellbeing, life satisfaction and forgiveness (Diener \& Lucas, 1999; Schimmack, Oishi, Furr \& Funder, 2004; Walker \& Gorsuch, 2002). Guiterrez, Jimenez, Hernandez and Puente (2005) indicated that extraversion and neuroticism dimensions of personality are strongly associated with subjective well-being and they found a positive correlation between openness to experience and the positive and negative components of affect. Milligan (2003) conducted a study with undergraduate students and demonstrated that optimism has positive correlations with extraversion, agreeableness, and strong negative relationships with neuroticism.

Subjective vitality can be discussed as a positive individual trait and as a dynamic reflection of well-being (Ryan \& Frederick, 1997). Ryan and Frederick (1997) defined subjective vitality as subjective experience of being full of energy and alive. Subjective vitality was improved within the framework of self-determination theory (Deci \& Ryan, 2000) and states presence of mental positive energy, a vital, cheerful, alerted, fully energized and fresh person (Fini, Kavousian, Beigy, \& Emami, 2010). Individuals who experience more subjective vitality are alerted, energetic, and vital (Bostic, Rubio, \& Hood, 2000) and this construct is closely related with feelings of vigor (McNair, Lorr, \& Droppleman, 1971). According to Muraven, Gagne and Rosman (2008) subjective vitality is "a positive, energetic, vital state that increases when people engage in behaviors that feel autonomous or self-driven, and decreases when people feel pressure to act” (p. 575).

Subjective vitality refers an inner energy that an individual may use for purposive actions and it both linked with psychological and physical factors. While psychological factors like being in love and positive affect increase subjective vitality, physical factors such as fatigue and illness may cause loss of energy, and may diminish one's vitality level (Ryan \&
Frederick, 1997). Subjective vitality also enhances being productive, active and helps to cope with stress better and to have better mental health (Ryan \& Deci, 2008). Earlier studies have showed that subjective vitality is positively related to subjective happiness (Uysal, Satici, \& Akin, 2013), emotional, psychological and social well-being, quality of life (Salama-Younes, 2011), and self-esteem (Ryan \& Frederick, 1997). On the other hand, subjective vitally was found negatively associated with depression, anxiety, psychologi$\mathrm{cal} /$ somatic distress, negative affectivity (Ryan \& Frederick, 1997) and poor self-control performance (Muraven, et al., 2008).

Most previous researchers have focused on the adaptive or maladaptive constructs and human strengths or weaknesses both related with and influencing subjective vitality, such as subjective happiness, life satisfaction, depression, anxiety, and overuse of Facebook (Ryan \& Frederick 1997; Salama-Younes, 2011; Uysal, et al., 2013). Vlachopoulos and Karavani (2009) indicated that subjective vitality was positively related with autonomy, competence and relatedness. Saricam (2015) indicated that subjective vitality was linked with school burnout and self-efficacy. Subjective vitality was also found negatively associated with the accepting external influences and self-alienation and positively associated with the authentic living (Göcet-Tekin \& Satici, 2014). Additionally, Ryan and Frederick (1997) examined subjective vitality in six studies with different variables and they investigated the associations between the five-factor personality model and subjective vitality by NEO Personality Inventory Revised (NEO-PI-R). They suggested that three Big Five traits (Neuroticism, Extraversion, and Conscientiousness) were significantly associated with subjective vitality. However, it is not clear whether these research findings from 102 American undergraduates can be generalized to different countries cultures and groups such as Turkish undergraduates. On the other hand, to our knowledge no recent study was published that has examined the association between personality traits and subjective vitality. Many researchers have suggested that well-being may be related to culture and it could differ from culture to culture (e.g., Schimmack, Oishi, Radhakrishnan, Dzokoto, \& Ahadi, 2002). Thus, the purpose of the present research was to investigate the association between the Big Five factors of personality and subjective vitality that can be accepted as a dynamic reflection of well-being in Turkish university students.

\section{Method}

\section{Participants}

Three hundred seven Turkish university students $(n=$ 180 females, 58.6\%; $n=127$ males, 41.4\%) from Yildiz Technical University and Anadolu University, participated in the study. Their collective mean age was 21.24 years $(S D=$ 1.21 , range $=18-26)$. Of the participants, $82(27 \%)$ were 
freshman, $74(24 \%)$ were sophomores, 91 (30\%) were juniors, and $60(19 \%)$ were seniors.

\section{Measures}

Adjective Based Personality Scale (ABPT). The ABPT (Bacanli, Ilhan, \& Aslan, 2009) includes 40 opposite adjective pairs (e.g., Optimist vs Pessimist). ABPT is consists of five sub-dimensions (extroversion, emotional stability/neuroticism, agreeableness, conscientiousness and openness to experiences). To examine the construct validity of ABPT, component analysis has been applied on the data obtained from 285 university students. Analyses have shown that the ABPT explains $52.63 \%$ of the variance in big five model. The factor loadings of ABPT were; .56 to .79 for extraversion, .60 to .77 for agreeableness, .66 to .86 for responsibility, .36 to .71 for emotional instability/neuroticism, and .49 to .79 for openness to experience. The internal consistency coefficients were $.80, .88, .89, .87$, and .73 and the test-retest reliability coefficients were $.68, .71, .85, .86$, and .85 , for five dimensions, respectively. Sociotrophy Scale, Reaction to Conflicts Scale, Negative-Positive Emotion Scale, and Trait Anxiety Inventory has been used to determine the concurrent validity of ABPT (Bacanli et al, 2009). ABPT was used to evaluate big five personality traits due to the psychometric properties of the ABPT were found to be satisfactory.

Subjective Vitality Scale (SVS). The SVS (Ryan \& Frederick, 1997) comprise of seven items (e.g., 'I look forward to each new day'). Participants rate on a Likert-type scale ranging from 1 'not at all true' to 'very true'. A total score ranges from 7 to 49 and higher score indicated that higher subjective vitality level. Akin, Satici, Arslan, Akin, and Kayis (2010) had done Turkish adaptation of this scale. Confirmatory factor analysis of Turkish version showed that the SVS was well fit with following indices; NFI $=.99$, CFI $=$ 1.00, GFI $=.99$, AGFI $=.99$, RMSEA $=.047$, and $\mathrm{SRMR}=.015$. The reliability of the scale is acceptable Cronbach's alpha for SVS Turkish version was .84 (Akin, et al., 2010). Cronbach's alpha for the seven items in this study was .84 .

\section{Procedure}

The Sampling was based on a convenience sampling approach. No incentives were awarded and voluntary participation was emphasized. The survey emphasized that responses are anonymous and confidential, and no identifying information was requested from participants. A paper-pencil questionnaire was given to the participants in the classroom, which took 10 minute to complete. All participants gave informed consent prior to starting the study. Association between big five personality traits and subjective vitality was analyzed with correlation coefficient. In addition, in order to determine predictive role of big five personality traits on subjective vitality hierarchical multiple regression was done.

\section{Results}

In Table 1 presents the correlational relations with the confidence interval, mean and standard deviations of the study variables.

Table 1. Correlations and descriptive statistics of study variables.

\begin{tabular}{|c|c|c|c|c|c|c|}
\hline Variables & 1 & 2 & 3 & 4 & 5 & 6 \\
\hline \multicolumn{7}{|l|}{ 1. Subjective vitality } \\
\hline 2. Openness & $.41^{* *}$ & & & & & \\
\hline $95 \% \mathrm{CI}$ & $(.31, .49)$ & & & & & \\
\hline 3. Consciousness & $.23^{* *}$ & $.29^{* *}$ & & & & \\
\hline $95 \%$ CI & $(.12, .33)$ & $(.18, .39)$ & & & & \\
\hline 4. Extraversion & $.49^{* *}$ & $.57^{* *}$ & $.49^{* *}$ & & & \\
\hline $95 \% \mathrm{CI}$ & $(.40, .57)$ & $(.49, .64)$ & $(.40, .57)$ & & & \\
\hline 5. Agreeableness & $.34^{* *}$ & $.32^{* *}$ & $.41^{* *}$ & $.41^{* *}$ & & \\
\hline $95 \% \mathrm{CI}$ & $(.24, .43)$ & $(.22, .42)$ & $(.31, .50)$ & $(.31, .50)$ & & \\
\hline 6. Neuroticism & $-.24^{* *}$ & $-.14^{*}$ & -.08 & $-.13^{*}$ & $-.38^{* *}$ & \\
\hline $95 \%$ CI & $(-.34,-.13)$ & $(-.25,-.03)$ & $(-.19, .03)$ & $(-.24,-.02)$ & $(-.47,-.28)$ & \\
\hline Mean & 33.45 & 41.47 & 35.93 & 44.11 & 49.24 & 24.88 \\
\hline SD & 6.91 & 6.10 & 5.53 & 8.01 & 6.51 & 5.98 \\
\hline Skewness & -.46 & -.18 & -.69 & -.26 & -.43 & .31 \\
\hline Kurtosis & .50 & -.33 & .34 & -.04 & .16 & -.16 \\
\hline
\end{tabular}

Notes: ${ }^{*} p<.05,{ }^{* *} p<.01$

As can be seen in Table 1, mean scores revealed that the participants tended to exhibit a moderate level of subjective vitality $(M=33.45, S D=6.91)$, openness to experience $(M$ $=41.47, S D=6.10)$, consciousness $(M=35.93, S D=5.53)$, extraversion $(M=44.11, S D=8.01)$, and agreeableness $(M$ $=49.24, S D=6.51)$. Furthermore, participants reports of their neuroticism were relatively low $(M=24.88, S D=$ 5.98). Subjective vitality was positively associated with openness, $r_{(307)}=.41,95 \%$ C.I. [.31, .49], consciousness, $r_{(307)}=$ $.23,95 \%$ C.I. $[.12, .33]$, extraversion, $r_{(307)}=.49,95 \%$ C.I. $[.40, .57]$, and agreeableness, $r_{(307)}=.34,95 \%$ C.I. $[.24, .43]$. 
Otherwise, subjective vitality was negatively associated with neuroticism, $r_{(307)}=-.24,95 \%$ C.I. [-.34, -.13].

\section{Hierarchical Regression Analyses}

First, assumptions of the multiple regression analyses were checked. Normal distribution of variables was checked by skewness and kurtosis values. Skewness values ranged from -.69 to .31 and kurtosis values ranged from -.16 to 1.34 , according to these values, the data could be acceptable as normal distribution. In addition, multicollinearity, variance inflation factor (VIF), and tolerance values were examined. All values were found as acceptable levels (VIF ranged from 1.17 to 1.59 and tolerance values ranged from .63 to .85). In addition, Durbin-Watson value was found as 1.47 and indicates that there is no autocorrelation. After met all assumptions, regression analysis was conducted. The hierarchical multiple regression analyses were conducted with subjective vitality as dependent variable, big five personality traits as independent variables (Table 2).

Table 2. Predictive role of big personality traits on subjective vitality.

\begin{tabular}{|c|c|c|c|c|c|c|c|c|c|c|c|c|c|c|c|c|c|c|c|c|}
\hline \multirow{2}{*}{ Variable } & \multicolumn{4}{|c|}{ Model 1} & \multicolumn{4}{|c|}{ Model 2} & \multicolumn{4}{|c|}{ Model 3} & \multicolumn{4}{|c|}{ Model 4} & \multicolumn{4}{|c|}{ Model 5} \\
\hline & $B$ & SE & $\beta$ & $t$ & $B$ & SE & $\beta$ & $t$ & $\bar{B}$ & SE & $\beta$ & $t$ & $B$ & SE & $\beta$ & $t$ & $B$ & SE & $\beta$ & $t$ \\
\hline Extraversion & .43 & .04 & .49 & $9.91^{* *}$ & .33 & .05 & .39 & $6.43^{* *}$ & .31 & .05 & .36 & $6.05^{* *}$ & .31 & .05 & .35 & $6.05^{* *}$ & .31 & .05 & .36 & $5.93^{* *}$ \\
\hline Openness & & & & & .21 & .07 & .19 & $3.11^{* *}$ & .16 & .07 & .14 & $2.35^{*}$ & .16 & .07 & .14 & $2.35^{*}$ & .16 & .07 & .14 & $2.35^{*}$ \\
\hline Agreeableness & & & & & & & & & .21 & .05 & .20 & $3.85^{* *}$ & .16 & .06 & .15 & $2.84^{* *}$ & .17 & .06 & .16 & $2.75^{* *}$ \\
\hline Neuroticism & & & & & & & & & & & & & -.13 & .06 & -.11 & $-2.23^{*}$ & -.13 & .06 & -.12 & $-2.20^{*}$ \\
\hline Conscious- & & & & & & & & & & & & & & & & & -.01 & .07 & .00 & -.15 \\
\hline \multicolumn{21}{|l|}{ ness } \\
\hline$\overline{\mathrm{R}^{2}}$ & \multicolumn{4}{|c|}{.244} & \multicolumn{4}{|c|}{.267} & \multicolumn{4}{|c|}{.301} & \multicolumn{4}{|c|}{.313} & \multicolumn{4}{|c|}{.313} \\
\hline Adj $R^{2}$ & \multicolumn{4}{|c|}{.241} & \multicolumn{4}{|c|}{.262} & \multicolumn{4}{|c|}{.294} & \multicolumn{4}{|c|}{.303} & \multicolumn{4}{|c|}{.301} \\
\hline$S E$ & \multicolumn{4}{|c|}{6.01} & \multicolumn{4}{|c|}{5.93} & \multicolumn{4}{|c|}{5.80} & \multicolumn{4}{|c|}{5.76} & \multicolumn{4}{|c|}{5.77} \\
\hline$F_{(d f \mathrm{n}, d f \mathrm{~d})}$ & \multicolumn{4}{|c|}{$98.19_{(1,305)}$} & \multicolumn{4}{|c|}{$55.35_{(2,304)}$} & \multicolumn{4}{|c|}{$43.54_{(3,303)}$} & \multicolumn{4}{|c|}{$34.33_{(4,302)}$} & \multicolumn{4}{|c|}{$27.38_{(5,301)}$} \\
\hline
\end{tabular}

Table 2 demonstrates hierarchical regression analysis results which have been entered according to correlation coefficients. When the Table 2 examining the four variables, except consciousness, predictor model was able to account for $31 \%$ of the variance in subjective vitality, $\mathrm{F}_{(5,301)}=27.38, p$ $<.001$. Extraversion entered the equation first, accounting for $24 \%$ of the variance in predicting subjective vitality $\left(R^{2}=\right.$ .244 , Adjusted $\left.R^{2}=.241\right)$. Then, openness to experience entered on the second step accounting for an additional $2.3 \%$ of the variance $\left(\Delta R^{2}=.023\right)$. Moreover, agreeableness entered on the third step accounting for an additional 3.4\% of the variance $\left(\Delta R^{2}=.034\right)$. Furthermore, neuroticism entered on the third step accounting for an additional 1.2\% of the variance $\left(\Delta \mathrm{R}^{2}=.012\right)$. In the last step, it was found that extraversion $(\beta=.36, p<.001)$, agreeableness $(\beta=.16, p<$ $.001)$, and openness $(\beta=.14, p<.01)$ significantly positive predicted subjective vitality, respectively. Conversely, neuroticism $(\beta=-.12, p<.01)$ significant negative predicted subjective happiness. Lastly, regression analysis indicated that consciousness did not significant predictor of subjective vitality.

\section{Discussion}

Several studies indicated that factors of personality may be closely associated with well-being (e.g. Doğan, 2012; Steel, Schmidt, \& Shultz, 2008) and other individual strengths (Walker \& Gorsuch, 2002; Wood, Joseoh, \& Maltby, 2009). From this point of view, this study aimed to investigate the association between five factor personality traits and subjective vitality as an individual strength and an integral to well- being (Fini, Kavousian, Beigy, \& Emami, 2010). The results of the current study indicated that openness, conscientiousness, extraversion and agreeableness are positively associated to subjective vitality, while neuroticism is negatively associated with subjective vitality. Moreover, results indicated that except consciousness, four dimensions of personality (neuroticism, extraversion, openness to experiences and agreeableness) predicted subjective vitality.

As predicted, results indicated that extraversion is the most significant predictor of subjective vitality and related positively with subjective vitality. Extraversion includes being active, energetic, assertive and outgoing (Kaiseler, Polman \& Nichols, 2012). Similarly, subjective vitality indicated positive energy and requires being alert, active and enthusiastic (Fini et al., 2010). Ryan and Frederick (2007) also found that subjective vitality was positively related to extraversion. Hence, it can be remarked that the results acquired from the present study is parallel to theoretical foundation as well.

Findings of the present study propounded that agreeableness predicted subjective vitality positively. Studies indicated that agreeableness had positive relationships with many variables which are indicators of well-being such as subjective well-being, self-esteem, and hope (Aslan, 2012; Doğan, 2013; Mutlu, Balbağ \& Cemrek, 2010). Likewise, Uysal and colleagues (2013) revealed that subjective vitality was positively associated with subjective happiness. Additionally, Ebstrup and colleagues (2011) found that agreeableness and perceived stress that correlated negatively. Similarly, in a research conducted by Salama-Younes and colleagues (2009) participants who reported less stress showed 
high vitality. Thus, the results of the past studies support findings of this research.

According to the results, openness to experience dimension of personality predicts subjective vitality and positively correlated with this construct. Research demonstrated that openness to experience negatively associated with depersonalization which is a dimension of burnout (Bakker, Van Der Zee, Lewig \& Dollard, 2006), emotional exhaustion, reduction of motivation and reduction of concentration (De Vries \& Van Heck, 2002). On the other hand, subjective vitality requires being vital, enthusiastic, non-fatigue and energetic (Fini et al., 2010). As a result of his study Sarıcam (2015) has found that subjective vitality also negatively related with school burnout. Finally, openness to experiences has positively associated with perceived coping ability (Penley \& Tomaka, 2002). Similarly, Ryan and Frederick (1997) claimed that in vital states individual cope better with stress.

It has been found that neuroticism sub dimension of personality is also a predictor of subjective vitality and negatively associated with this variable. Depression and anxiety are to main facets of neuroticism (Costa \& McCrae, 1992; McCrae \& John, 1992; Ryan \& Frederick, 1997). Previous studies revealed that subjective vitality was negatively linked to depression, anxiety, negative affectivity, somatic distress and physical symptoms (Ryan \& Frederick, 1997). Ryan and Frederick also showed that subjective vitality had a significant negative association with neuroticism. Samarein and colleagues (2013) in their researches identified significant negative relations with internet addiction and neuroticism. Uysal and colleagues (2013) also concluded that subjective vitality negatively related to Facebook addiction. Therefore, these findings seem to be consistent with previous literature.

As demonstrated by present research conscientiousness has positive correlation with subjective vitality and not predicted subjective vitality significantly. In a similar way, Ryan and Frederick (1997) demonstrated that conscientiousness positive associated with subjective vitality. Doğan (2013) in his research stated that conscientiousness was positive related to subjective well-being. Subjective happiness also found positive related with subjective vitality (Uysal et al., 2013). Thus, this results acquired from the present study is parallel to theoretical foundation as well.

\section{Limitations and Future Directions}

This research also has limitations. Firstly, this research employs a cross-sectional method which obstructs to make definite causal claims on the relationships among the variables. Therefore, longitudinal or experimental studies may be conducted to determine how personality traits might affect one's vitality and to establish the direction of causality. Secondly, data were collected from university students studying in universities in Turkey at a single point in time. Therefore, generalizability of the findings is limited. In the future, random sampling can be used to allow a cohort effect in different region. Furthermore, cross-cultural studies can be con- ducted in order to determine the relationship between personality traits and vitality among individualistic and collectivistic cultures. Thirdly, only one variable, personality, is tested as a predictor of subjective vitality. Other variables that may predict subjective vitally should be tested. Besides, future studies may investigate variables such as cognitive flexibility and psychological vulnerability that may mediate the relation between personality traits and vitality. Lastly, to collect data only self-report measures were used and future research should attempt to include other sources of data. Future studies may use multiple assessment methods such as observations, peer-assessments and interviews to strengthen the validity of the findings. In the data collection process of this study, it was observed that university students were not particularly excited by answering the items in the scales. Therefore, giving incentives would be sensible to enhance their motivation to participate the study.

\section{Theoretical and Practical Implications}

Personality traits shows us what kind of risk factors a student may face in their lives (e.g., Dong, Wang, Yang, \& Zhou, 2012; Matsudaira, \& Kitamura, 2006). Therefore, counselling centers should pay more attention to the students who have high levels of neuroticism and other traits involving risk factors which in turn may yield to maladaptive patterns of behavior. Also, our study revealed that subjective vitality was predicted negatively by neuroticism. For this reason, especially, counselling centers should take necessary steps to make those students with high in neuroticism become more energetic, vital and enthusiastic with an increase in well-being. High levels of neuroticism can be decreased and vitality can be strengthened through interventions such as psycho-educational group, group counseling, and training program etc.

The possibility of using psychological, physiological, social and academic potentials effectively will increase by achieving high levels of vitality (e.g., Uysal, Satici, Satici, \& Akin, 2014; Ryan, et al., 2010), which in return will provide positive outcomes on behalf of both the individual himself/herself and the society. Besides these, other personality traits should not be ignored as well. In our study revealed that extraversion, agreeableness, and openness also predict subjective vitality of the students positively. Therefore, universities should provide their students with places and activities which encourage interaction and communication with each other by increasing their extraverted qualities. Moreover, well-structured intervention programs should also be prepared to increase students' adaptive behaviors and extraverted qualities by counselling centers.

\section{Conclusions}

Consequently, results show that big five personality traits are effective on subjective vitality which is an important concept in positive psychology. Research on positive psychology is 
rapidly growing in the new millennia. Thus, the current study will make a contribution to extant literature on positive psychology and personality and will broadens understanding of how the Big Five influences subjective vitality in Turkish youth. Additionally, this study adds to the scant literature on the constructs related to subjective vitality in

\section{References}

Akin, A., Satici, S. A., Arslan, S., Akin, U., \& Kayis, A. R. (2012, February). The validity and the reliability of the Turkish version of the Subjective Vitality Scale (SVS). In 4rd World Conference on Educational Sciences, Barcelona, Spain.

Allen, M. S., Greenlees, I., \& Jones, M. V. (2011). An investigation of the five factor model of personality and coping behaviour in sport. Journal of Sports Sciences, $29, \quad 841-850$. http://dx.doi.org/10.1080/02640414.2011.565064

Allport, G. W. (1961). Pattern and Growth in Personality. New York: Holt, Rinehart \& Winston.

Aslan, S. (2012). Prediction of five factor personality dimensions through self-esteem in Turkish late adolescents. Journal of Erzincan Faculty of Education, 14(1), 25-40.

Atkinson, R. L., Atkinson, R. C., Smith, E. E., Bem, D. J., \& NolenHoeksema, S. (1996). Introduction to Psychology. (Translator: Yavuz Alagon). Ankara: Arkadaş Publishing.

Bacanli, H., Ilhan, T. \& Arslan, S. (2009). Developing a personality scale based on Five Factor Theory: Adjective Based Personality Scale (ABPT), Türk Eğitim Bilimleri Dergisi, 7(2), 261- 279.

Bakker, A. B., Van Der Zee, K. I., Lewig, K. A., \& Dollard, M. F. (2006). The relationship between the big five personality factors and burnout: A study among volunteer counselors. The Journal of Social Psychology, 146(1), 31-50. http://dx.doi.org/10.3200/SOCP.146.1.31-50

Burger, J. M. (2006). Personality. (Translator: Inan Deniz Erguvan Sarioglu), Istanbul: Kaknüs Publishing.

Costa, P. T., \& McCrae, R. R. (1985). The NEO Personality Inventory manual, Odessa, FL: Psychological Assessment Resources.

De Vries, J., \& Van Heck, G. L. (2002). Fatigue: relationships with basic personality and temperament dimensions. Personality and Individual Differences, 33(8), 1311-1324. http://dx.doi.org/10.1016/S01918869(02)00015-6

Deci, E. L., \& Ryan, R. M. (2000). The" what" and" why" of goal pursuits: Human needs and the self-determination of behavior. Psychological In$\begin{array}{lll}\text { quiry, } & 11(4), & 227-268 .\end{array}$ http://dx.doi.org/10.1207/S15327965PLI1104 01

Diener, E., \& Lucas, R. (1999). Personality and subjective well-being. In D. Kahneman, E. Diener, \& N. Schwarz (Eds.), Well-being: Foundations of hedonic psychology (pp. 213-229). New York: Russell Sage Foundation.

Digman, J. M. (1990). Personality structure: Emergence of the five-factor model. Annual Review of Psychology, 41, 417-440. http://dx.doi.org/10.1146/annurev.ps.41.020190.002221

Doğan, T. (2012). The five factor personality traits and subjective wellbeing. Doğus University Journal, 14(1), 56-64.

Dong, G., Wang, J., Yang, X., \& Zhou, H. (2013). Risk personality traits of Internet addiction: a longitudinal study of Internet-addicted Chinese university students. Asia-Pacific Psychiatry, 5(4), 316-321. http://dx.doi.org/10.1111/j.1758-5872.2012.00185.x

Ebstrup, J. F., Eplov, L. F., Pisinger, C., \& Jørgensen, T. (2011). Association between the Five Factor personality traits and perceived stress: is the effect mediated by general self-efficacy? Anxiety, Stress and Coping, 24(4), 407-419. http://dx.doi.org/10.1080/10615806.2010.540012

Eysenck, H. J. (2013). The Structure of Human Personality. New York: Routledge.

Fini, A. A. S., Kavousian, J., Beigy, A., \& Emami, M. (2010). Subjective vitality and its anticipating variables on students. Procedia-Social and Behavioral Sciences, 5, 150-156. http://dx.doi.org/10.1016/i.sbspro.2010.07.064

Friedman, H. S., \& Schustack, M. W. (2011). Personality: Classic Theories and Modern Research (5 $5^{\text {th }}$ Ed.). Needham Heights, MA: Allyn and Bacon.
Turkey. Future studies should examine the possible predictive role of other variables on subjective vitality.

Acknowledgement.- We are grateful to Professor Hasan Bacanli because of giving permission to use Adjective Based Personality Scale.

Gocet-Tekin, E., \& Satici, B. (2014). An investigation of the predictive role of authenticity on subjective vitality. Educational Sciences: Theory \& Practice, 14(6), 2063-2070. http://dx.doi.org/10.12738/estp.2014.6.2216

Gutierrez, J. L. G., Jimenez, B. M., Hernandez, E. G., \& Puente, C. (2005). Personality and subjective well-being: Big five correlates and demographic variables. Personality and Individual Differences, 38(7), 1561-1569. http://dx.doi.org/10.1016/j.paid.2004.09.015

John, O. P., \& Srivastava, S. (1999). The big five trait taxonomy: History, measurement, and theoretical perspectives. In L. A. Pervin \& O. P. John (Eds.), Handbook of Personality: Theory and Research (2 ${ }^{\text {nd }}$ ed., pp. $102-$ 139). New York: Guilford Press.

Kaiseler, M., Polman, R. C., \& Nicholls, A. R. (2012). Effects of the Big Five personality dimensions on appraisal coping, and coping effectiveness in sport. European Journal of Sport Science, 12(1), 62-72. http://dx.doi.org/10.1080/17461391.2010.551410

Larsen, R. J., \& Buss, D. M. (2005). Personality Psychology: Domains of Knowledge about Human Nature (2nd Ed.). New York: McGraw Hill.

Matsudaira T, Kitamura T. (2006). Personality traits as risk factors of depression and anxiety among Japanese students. Journal of Clinical Psychology, 62, 97-109. http://dx.doi.org/10.1002/jclp.20215

McCrae, R. R., \& Costa, P. T. (1987). Validation of the five-factor model of personality across instruments and observers. Journal of Personality and Social Psychology, 52(1), 81-90. http://dx.doi.org/10.1037/00223514.52.1.81

McCrae, R. R., \& Costa, P. T. (1997). Personality trait structure as a human universal. American Psychologist, 52(5), 509-516. http://dx.doi.org/10.1037/0003-066X.52.5.509

McCrae, R. R., \& John, O. P. (1992). An introduction to the five-factor model and its applications. Journa1 of Personality, 60, 175-2 15. http://dx.doi.org/10.1111/j.1467-6494.1992.tb00970.x

Milligan, M. (2003). Optimism and the five-factor model of personality, coping, and health behavior (Doctoral dissertation, Auburn University).

Muraven, M., Gagne, M., \& Rosman, H. (2008). Helpful self-control: Autonomy support, vitality, and depletion. Journal of Experimental Social Psychology, 44(3), 573-585. http://dx.doi.org/10.1016/j.jesp.2007.10.008

Mutlu, T., Balbag, Z., \& Cemrek, F. (2010). The role of self-esteem, locus of control and big five personality traits in predicting hopelessness. Procedia-Social and Behavioral Sciences, 9, 1788-1792. http://dx.doi.org/10.1016/j.sbspro.2010.12.401

Penley, J. A., \& Tomaka, J. (2002). Associations among the Big Five, emotional responses, and coping with acute stress. Personality and Individual Differences, 32(7), 1215-1228. http://dx.doi.org/10.1016/S01918869(01)00087-3

Ryan, R. M., \& Deci, E. L. (2008). A self-determination theory approach to psychotherapy: The motivational basis for effective change. Canadian Psychology, 49(3), 186. http://dx.doi.org/10.1037/a0012753

Ryan, R. M., \& Frederick, C. (1997). On energy, personality, and health: Subjective vitality as a dynamic reflection of well-being. Journal of Personality, 65(3), 529-565.

Ryan, R. M., Weinstein, N., Bernstein, J., Brown, K.W., Mistretta, L., \& Gagne, M. (2010). Vitalizing effects of being outdoors and in nature. Journal of Environmental Psychology, 30(2), 159-169. http://dx.doi.org/10.1016/j.jenvp.2009.10.009

Ryckman, R. (2008). Theories of Personality. Belmont: Thompson Wadsworth.

Salama-Younes, M. (2011). Positive mental health, subjective vitality and satisfaction with life for French physical education students. World Journal of Sport Sciences, 4(2), 90-97. 
Samarein, Z. A., Far, N. S., Yekleh, M., Tahmasebi, S., Yaryari, F., Ramezani, V., \& Sandi, L. (2013). Relationship between personality traits and Internet addiction of students at Kharazmi University. International Journal of Psychology and Behavioral Research, 2(1), 10-17.

Saricam, H. (2015). Mediating role of self-efficacy on the relationship between subjective vitality and school burnout in Turkish adolescents. International Journal of Educational Researchers, 6(1), 1-12.

Schimmack, U., Oishi, S., Furr, R. M., \& Funder, D. C. (2004). Personality and life satisfaction: A facet-level analysis. Personality and Social Psychology Bulletin, 30(8)

1062-1075.

http://dx.doi.org/10.1177/0146167204264292

Steel, P., Schmidt, J., \& Shultz, J. (2008). Refining the relationship between personality and subjective well-being. Psychological Bulletin, 134(1), 138161.

Uysal, R., Satici, S. A., \& Akin, A. (2013). Mediatıng effect of Facebook ${ }^{\circledR}$ addiction on the relationship between subjective vitality and subjective happiness. Psychological Reports, 113(3), 948-953. http://dx.doi.org/10.2466/02.09.18.PR0.113x32z3

Uysal, R., Satici, S. A., Satici, B., \& Akin, A. (2014). Subjective vitality as mediator and moderator of the relationship between life satisfaction and subjective happiness. Educational Sciences: Theory and Practice, 14(2), 489497. http://dx.doi.org/10.12738/estp.2014.2.1828

Vlachopoulos, S. P., \& Karavani, E. (2009). Psychological needs and subjective vitality in exercise: a cross-gender situational test of the needs universality hypothesis. Hellenic Journal of Psychology, 6, 207-222

Walker, D. F., \& Gorsuch, R. L. (2002). Forgiveness within the Big Five personality model. Personality and Individual Differences, 32(7), 1127-1137. http://dx.doi.org/10.1016/S0191-8869(00)00185-9

Wood, A. M., Joseph, S., \& Maltby, J. (2009). Gratitude predicts psychological well-being above the Big Five facets. Personality and Individual Differences, 46(4), 443-447. http://dx.doi.org/10.1016/j.paid.2008.11.012

(Article received: 23-06-2016; revised: 09-12-2016; accepted: 16-01-2017) 